\title{
Minimally invasive laparoscopic and robot- assisted emergency treatment of strangulated giant hiatal hernias: report of five cases and literature review
}

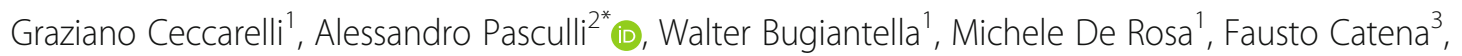
Fabio Rondelli ${ }^{1}$, Gianluca Costa ${ }^{1}$, Aldo Rocca ${ }^{4}$, Mattia Longaroni ${ }^{1}$ and Mario Testini ${ }^{2}$

\begin{abstract}
Background: Giant hiatal hernia $(\mathrm{GHH})$ is a condition where one-third of the stomach migrates into the thorax. Nowadays, laparoscopic treatment gives excellent postoperative outcomes. Strangulated GHH is rare, and its emergent repair is associated with significant morbidity and mortality rates. We report a series of five cases of strangulated $\mathrm{GHH}$ treated by a minimally invasive laparoscopic and robot-assisted approach, together with a systematic review of the literature.
\end{abstract}

Methods: During 10 years (December 2009-December 2019), 31 patients affected by GHH were treated by robotassisted or conventional laparoscopic surgical approach. Among them, five cases were treated in an emergency setting. We performed a PubMed MEDLINE search about the minimally invasive emergent treatment of GHH, selecting 18 articles for review.

Results: The five cases were male patients with a mean age of $70 \pm 18$ years. All patients referred to the emergency service complaining of severe abdominal and thoracic pain, nausea and vomiting. CT scan and endoscopy were the main diagnostic tools. All patients showed stable hemodynamic conditions so that they could undergo a minimally invasive attempt. The surgical approach was robotic-assisted in three patients (60\%) and laparoscopic in two (40\%). Patients reported no complications or recurrences.

Conclusion: Reviewing current literature, no general recommendations are available about the emergent treatment of strangulated hiatal hernia. Acute mechanical outlet obstruction, ischemia of gastric wall or perforation and severe bleeding are the reasons for an emergent surgical indication. In stable conditions, a minimally invasive approach is often feasible. Moreover, the robot-assisted approach, allowing a stable 3D view and using articulated instruments, represents a reasonable option in challenging situations.

Keywords: Giant hiatal hernia, Paraesophageal hernia, Emergency surgery, Laparoscopy, Robotic surgery

\footnotetext{
* Correspondence: pascullialessandro@gmail.com

"Unit of General Surgery "V. Bonomo", Department of Biomedical Sciences and Human Oncology, University of Bari "A. Moro", Polyclinic of Bari, Piazza Giulio Cesare 11, 70124 Bari, Italy

Full list of author information is available at the end of the article
}

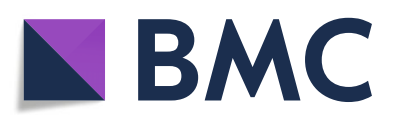

( ) The Author(s). 2020 Open Access This article is licensed under a Creative Commons Attribution 4.0 International License, which permits use, sharing, adaptation, distribution and reproduction in any medium or format, as long as you give appropriate credit to the original author(s) and the source, provide a link to the Creative Commons licence, and indicate if changes were made. The images or other third party material in this article are included in the article's Creative Commons licence, unless indicated otherwise in a credit line to the material. If material is not included in the article's Creative Commons licence and your intended use is not permitted by statutory regulation or exceeds the permitted use, you will need to obtain permission directly from the copyright holder. To view a copy of this licence, visit http://creativecommons.org/licenses/by/4.0/. The Creative Commons Public Domain Dedication waiver (http://creativecommons.org/publicdomain/zero/1.0/) applies to the data made available in this article, unless otherwise stated in a credit line to the data. 


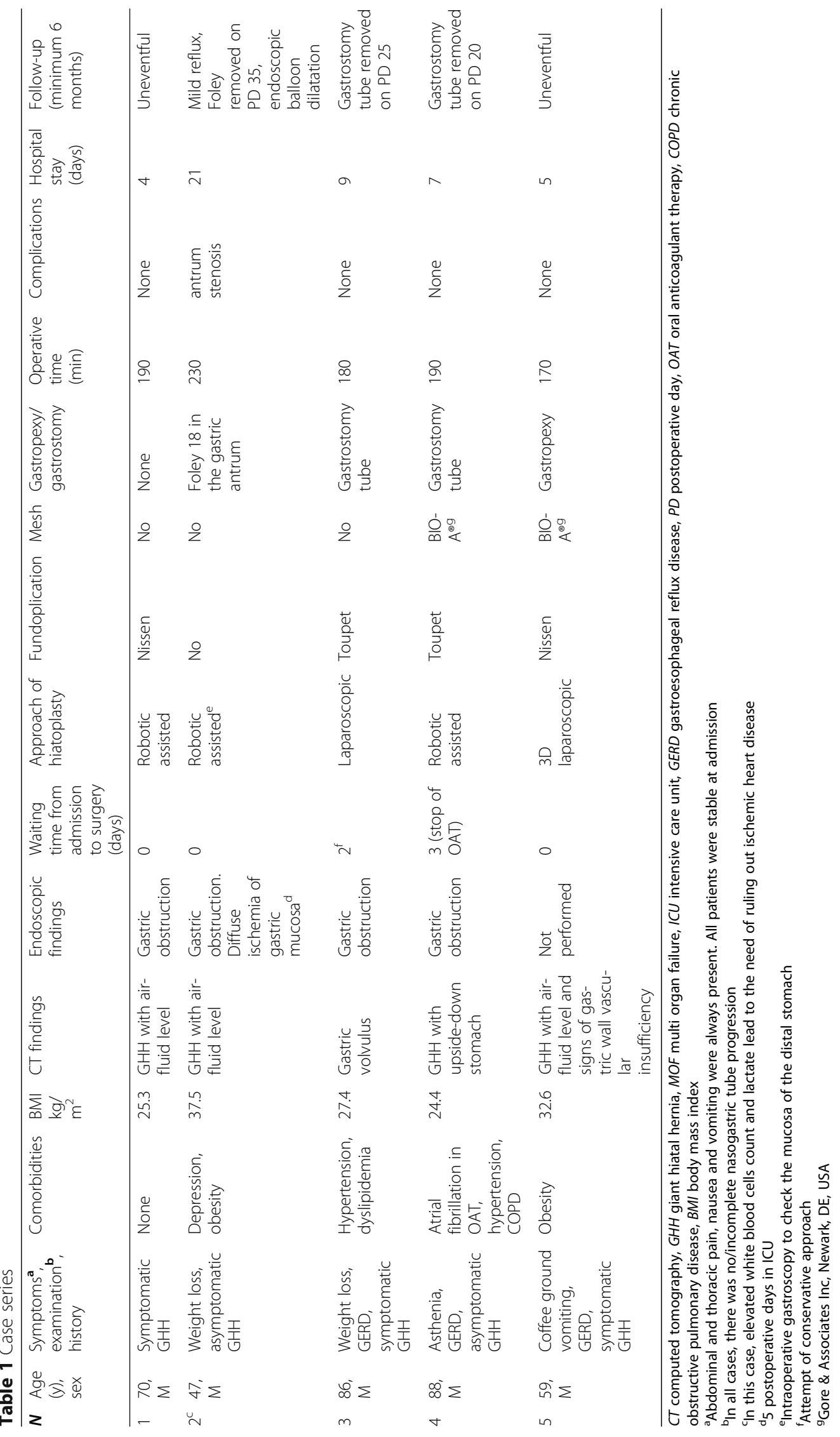




\section{Background}

Paraesophageal hernias represent 5 to $10 \%$ of all hiatal hernias $(\mathrm{HH})$, and their incidence is increasing mainly because of the ageing of the population. They are classified into four types [1]. In type I (sliding HH), there is a widening of the muscular hiatal tunnel and circumferential laxity of the phrenoesophageal membrane, allowing a portion of the gastric cardia to herniate upwards. In type II, the gastric fundus herniates into the thorax, but the gastroesophageal junction maintains its normal position. Type III is the association of type II with the migration of the gastroesophageal junction into the thorax (it represents the $90 \%$ of all paraesophageal hernias). Type IV is associated with the migration of other viscera through the hiatus. Giant hiatal hernia $(\mathrm{GHH})$ is a condition in which one-third or more of the stomach migrates into the thorax [2]. Primary GHH can be asymptomatic or can lead to chronic low-grade symptoms, such as heartburn, abdominal pain, early satiety, dysphagia, chest discomfort and dyspnoea. If they are present, there is a clear indication for elective surgical treatment. Severe acute symptoms are very uncommon $[3,4]$.

Rarely, GHH may present as an acute emergency due to the intrathoracic twisting of the stomach followed by mechanic obstruction. Acute gastric outlet symptoms, haemorrhage (mucosal bleeding of the stomach), gastric ischemia and perforation, are severe sequelae of strangulation or upside-down stomach $[5,6]$. All these complications represent real life-threatening conditions, with a high mortality rate (up to $30 \%$ ) $[7,8]$. Other intraabdominal organs, such as colon, spleen and small intestine, can be involved in the herniation [6, 7].

Since its first description in 1992, laparoscopic approach to symptomatic patients with both $\mathrm{HH}$ and $\mathrm{GHH}$ has gained broad consent and is now considered the gold standard for elective surgery, given its low mortality and morbidity [2, 7, 9-11]. Moreover, it is considered safe also in an emergency setting [12], especially in clinically stable patients. When available, even the robot-assisted approach may represent a valid option, giving the well-known postoperative benefits of minimally invasive procedures [13, 14]. However, in the case of unfit or unstable patients, the open approach remains mandatory.

Surgical emergency treatment provides the reduction of the migrated stomach with the excision of the hernia sac. The hiatal defect closure (direct or with mesh) may be followed by an anti-reflux procedure (according to Toupet or Nissen) or gastropexy [2, 10, 15, 16]. Nevertheless, prosthetic mesh reinforcement is overall accepted since its introduction has reduced the risk of recurrences [15, 17, 18]. Particular care is mandatory during gastric wall handling. Necrotic gastric wall or perforation may require gastric resection so that a fundoplication should be avoided. Collis-Nissen procedure may be necessary due to the presence of oesophageal shortening [19-21].

\section{Trocar disposition}

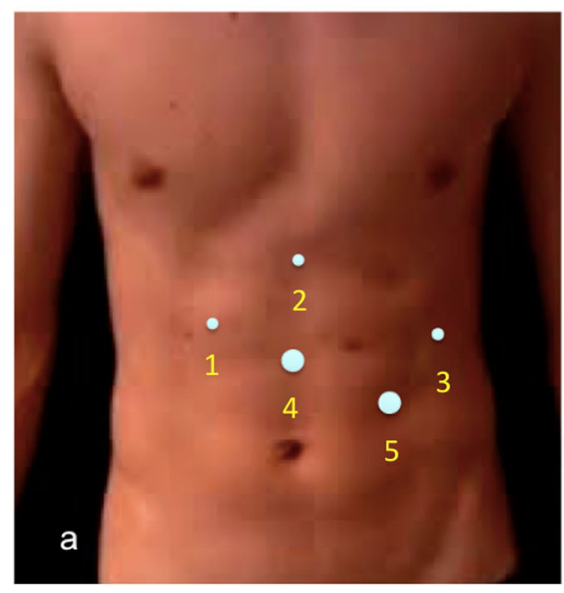

Laparoscopic approach

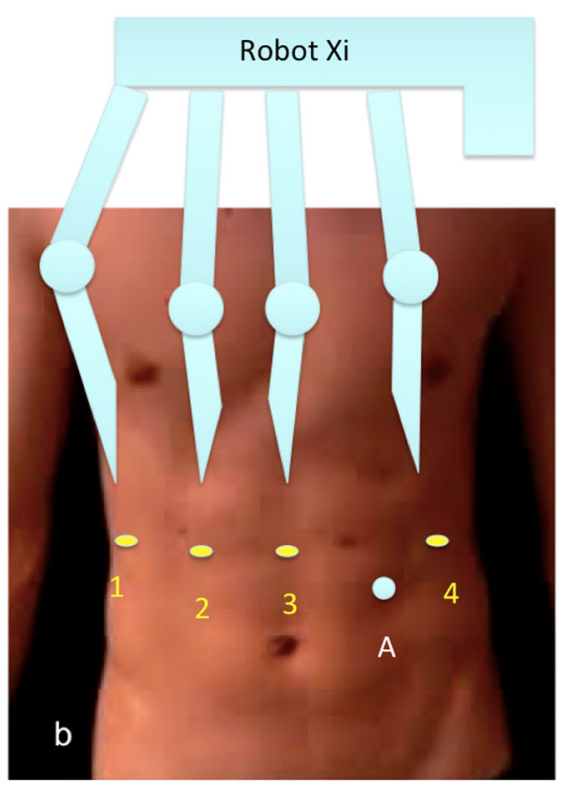

Robotic-assisted approach (Xi device) 

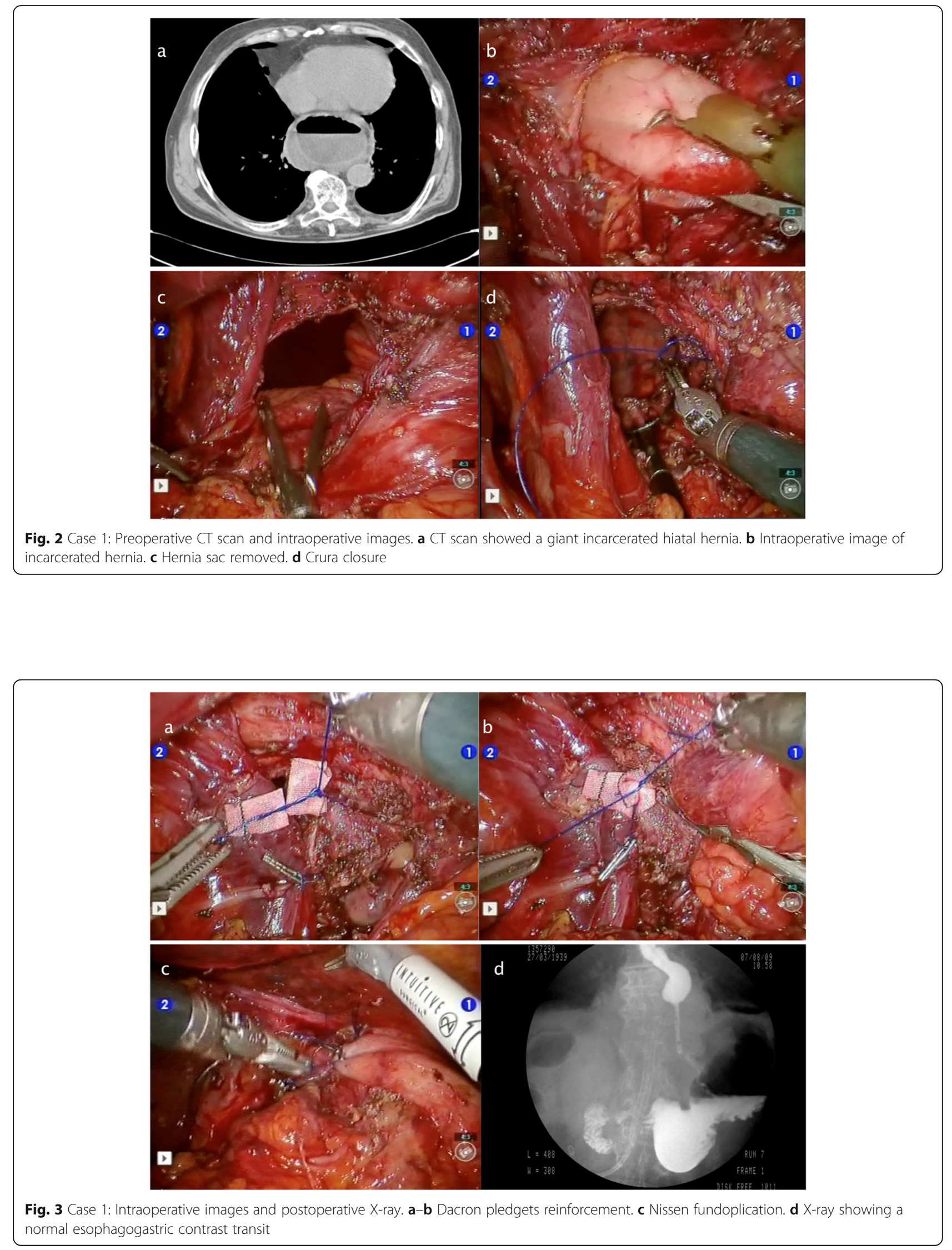
Compared to elective surgery, emergency procedures are related to a higher risk of morbidity and mortality $[22,23]$. No high-level evidence is available about emergency management of this rare condition.

In a recent multi-institutional broad database study from the USA, robotic-assisted repair accounted for the $6 \%$ of all emergent cases and $8 \%$ of all minimally invasive treated ones [14]. Our aim, along with the evaluation of the feasibility and safety of the robotic-assisted approach, was to infer suggestions from the current literature about the minimally invasive management of $\mathrm{GHH}$ in emergency.

\section{Case series}

During 10 years (December 2009-December 2019), 31 patients underwent surgery for $\mathrm{GHH}$ at our centre. All patients were treated using a robot-assisted or conventional laparoscopic surgical approach; the choice of robotic technology depended on the device's availability. Among them, five cases were treated in an emergency setting because of complicated GHH. No open surgery cases were recorded in the same period. Informed consent for the surgical procedure was always obtained before the treatment.

Table 1 sums up the characteristics of the patients: mean age was $70 \pm 18$ years (range $47-88$ ), and all patients were male. Most of the patients $(60 \%)$ had a history of known symptomatic $\mathrm{HH}$; in 3 cases, there was a history of gastroesophageal reflux disease (GERD).

All patients referred to the emergency service complaining of severe abdominal and thoracic pain, nausea and vomiting lasting from some hours (case 2) to 3 days (case 5). Case 5 presented with coffee-ground vomit. In all cases, the examination revealed diffuse abdominal tenderness and incomplete or impossible nasogastric tube progression. Laboratory tests were not specific; nevertheless, in case 3 , the elevated white cells count and lactate level, led to the need for ruling out ischemic heart disease.

All patients underwent electrocardiogram, chest X-ray and contrast-enhanced computed tomography (CT) scan of the chest and abdomen. The most common CT scan finding was air-fluid level in the context of a GHH. Most of the cases (80\%) underwent endoscopy before surgery, that always showed gastric obstruction, and in case 2 diffuse ischemia of the gastric mucosa. Most of the patients (60\%) underwent immediate surgery, except for case 3, where there was a conservative attempt because of the age, and for case 4 , in which surgery occurred after 3 days of OAT stop. All patients showed stable hemodynamic conditions so that they could undergo a minimally invasive attempt. The average waiting time from admission to surgery was 1 day $(0-3)$.

The surgical approach was robotic-assisted in 3 patients $(60 \%)$, laparoscopic in the remaining 2 . The Da
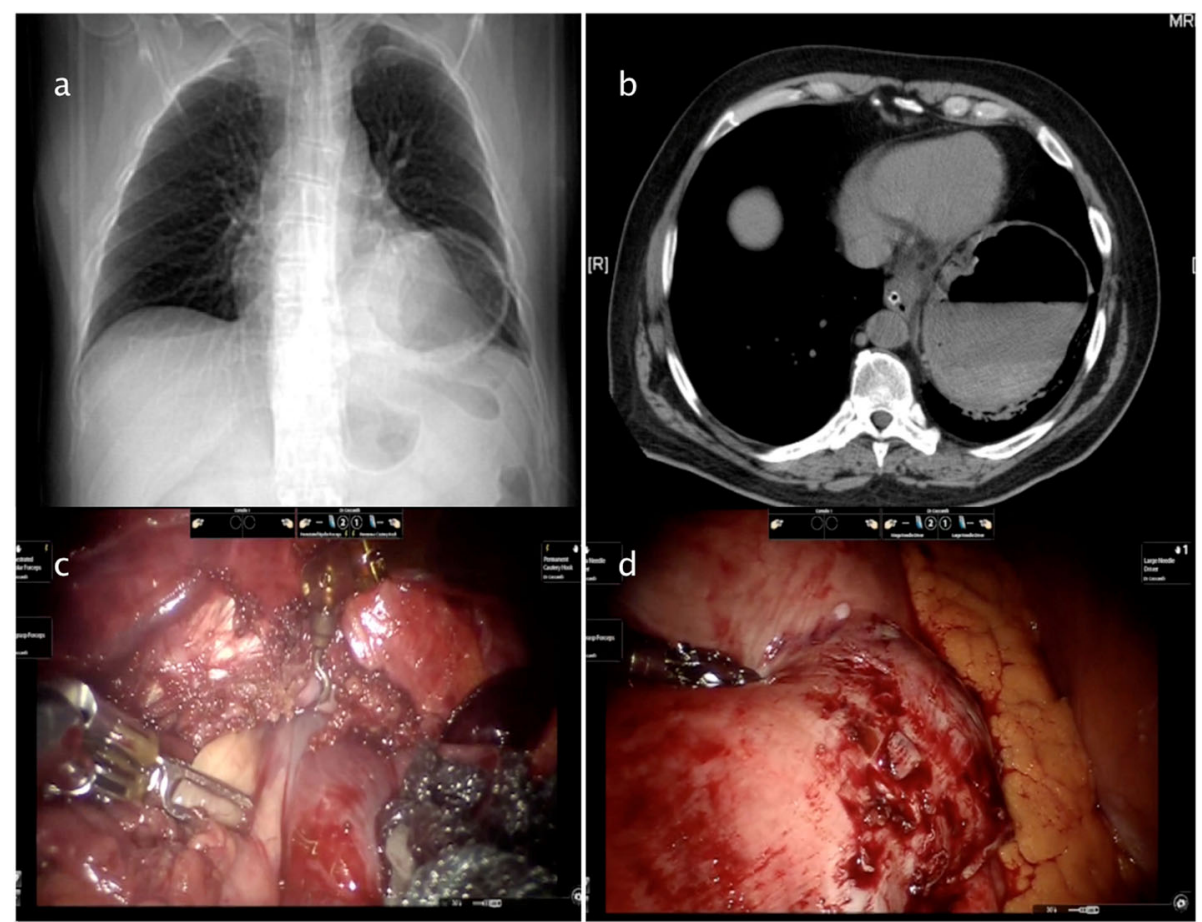

Fig. 4 Case 2: Preoperative radiologic exams and intraoperative images. a-b Chest radiography and chest-abdomen CT scan showing an air-fluid level at the posterior mediastinum. c-d Gastric reduction after hiatal defect enlargement 
Vinci Xi Robotic System (Intuitive Surgical, Inc. Sunnyvale, CA, USA) was used. The operation was always carried out by placing ports in the same fashion as an elective hiatoplasty (Fig. 1). The robotic cart was placed at the left side of the patient, at head-height. We placed the camera through the sopra-umbilical port, the monopolar cautery hook through the left one and the bipolar forceps through the middle-right port. The right robotic arm was used to retract the left liver lobe by the needle driver (replaced by another arm when needed for suturing). In robotically treated cases, we also placed an accessory 5-mm port. In laparoscopically treated cases, a 5-mm sub-xiphoidal port was used to retract the liver.

Figures 2, 3, 4, 5 and 6 reproduce imaging and intraoperative findings of the first three cases. The hook was used to lyse the adhesions of the hernia sac with mediastinal structures, while the herniated stomach and omentum were gently reduced in the abdomen. All patients showed type II/III hiatal hernias, with no cases of migration of other viscera through the hiatus. In case 2, the reduction of the hernia content in the abdomen was carried out only after the hiatal defect enlargement using ultrasound scalpel. After the reduction of the hernia content, the sac was removed, and the diaphragmatic crura and oesophagus were isolated. In the first 3 cases, the hiatoplasty was performed with polypropylene $2 / 0$ stitches and non-absorbable pledgets. In the last 2 cases, a BIO-A (Gore \& Associates Inc, Newark, DE, USA) resorbable prosthesis and pledgets were employed, secured with resorbable $2 / 0$ stitches.

Four patients $(80 \%)$ underwent Nissen and Toupet fundoplication: each in two cases, respectively. The choice between the two techniques depended on the obtainment of a floppy gastric valve. In case 2, because of the known ischemia of the gastric mucosa and the evidence of ischemic gastric serosa during the abdominal exploration, an intra-operative endoscopy was requested after the hernia reduction to check for the antrum and pylorus mucosa. After the careful evaluation of the whole stomach blood supply, we avoided gastric resection and fundoplication. In most of the cases (60\%), a gastrostomy (cases 2, 3 and 4)

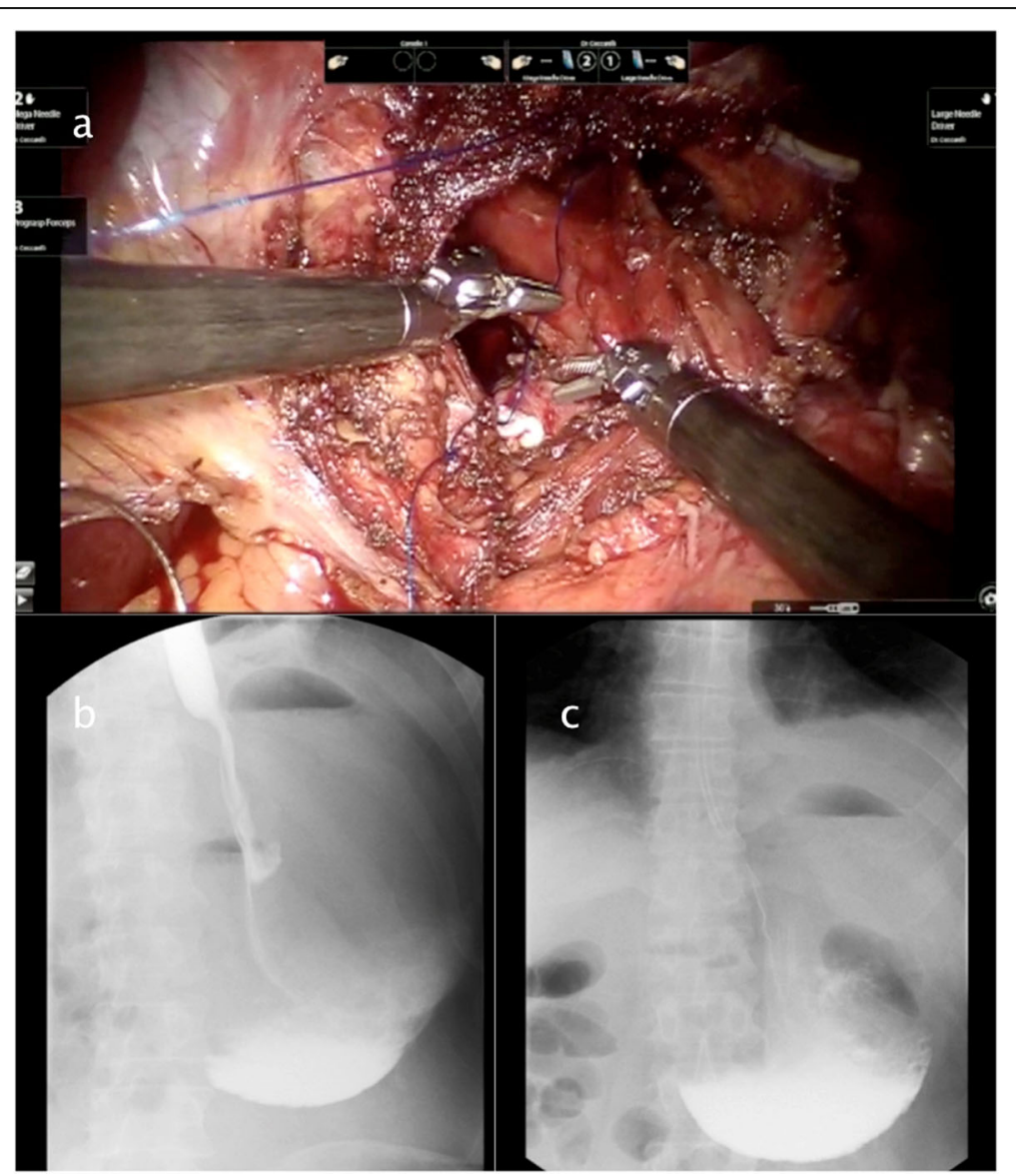

Fig. 5 Case 2: Intraoperative images and postoperative X-ray. a Hiatoplasty. b-c A 10 postoperative days X-ray swallow showing a good oesophagogastric transit with antrum stenosis, treated by several pneumatic dilatation after patient discharge from the hospital 
secured the stomach to the abdominal wall. Case 5 underwent a gastropexy. The mean operative time was $192 \pm 22.8 \mathrm{~min}$.

The postoperative course was uneventful for most of the cases $(80 \%)$. In case 2, the gastric mucosa ischemia and the difficult intubation led to a 5-day course in the intensive care unit, where the patient was monitored for the gastric perforation risk. The same patient developed antrum stenosis that healed after endoscopic treatment. The mean hospital stay was $9.2 \pm 6.9$ days (range 4-21).

Follow-up was carried out for a minimum of 6 months, with contrast X-ray of the upper gastrointestinal tract. Patients reported no complications or recurrences, and, when present, gastrostomy tubes were removed after 1 month from the operation.

\section{Review of literature}

We performed a PubMed MEDLINE search during January 2020 using the following words: "hiatal hernia" AND "emergency OR emergent OR urgency OR urgent" AND "laparoscopy OR robotic OR minimally invasive". Of the 77 found articles, we excluded articles not regarding humans (5), not in English (11) and not on adults (5). The 56 resulting papers were further investigated in terms of article design and subject matter excluding case reports and reviews (19) and articles about secondary hiatal hernias or elective procedures only (19); 18 articles were finally reviewed.

Table 2 shows data from the selected articles, reporting the number of patients not electively treated and through a minimally invasive approach. In those articles where it was not possible to obtain information regarding the urgent/emergent laparoscopically treated patients, we reported data from a larger cohort of patients, including those undergoing elective or open surgery.

No randomised trial is available regarding the preoperative workup, nor the timing of surgery, nor the use and type of mesh or additional procedures, such as fundoplication, gastrostomy or gastropexy, so that no strong recommendations can be drawn.

Demographic data suggest no definite difference in sex distribution, although it seems that complicated hiatal hernia mostly affects the seventh and eighth decade [2441]. The pathophysiology of $\mathrm{HH}$ is still unclear: increasing of intra-abdominal pressure and congenital or acquired widening of the diaphragmatic hiatus (weakness of the muscular crura due to elastin, collagens and matrix metalloproteinases abnormalities) are the most likely causes [42-44]. In the elderly, indeed, paraesophageal hernia is often asymptomatic, and the debate on whether to treat or not an asymptomatic patient is still active, following the high morbidity and mortality rate in elective repair $[4,10,16]$. Recently, pre-treatment

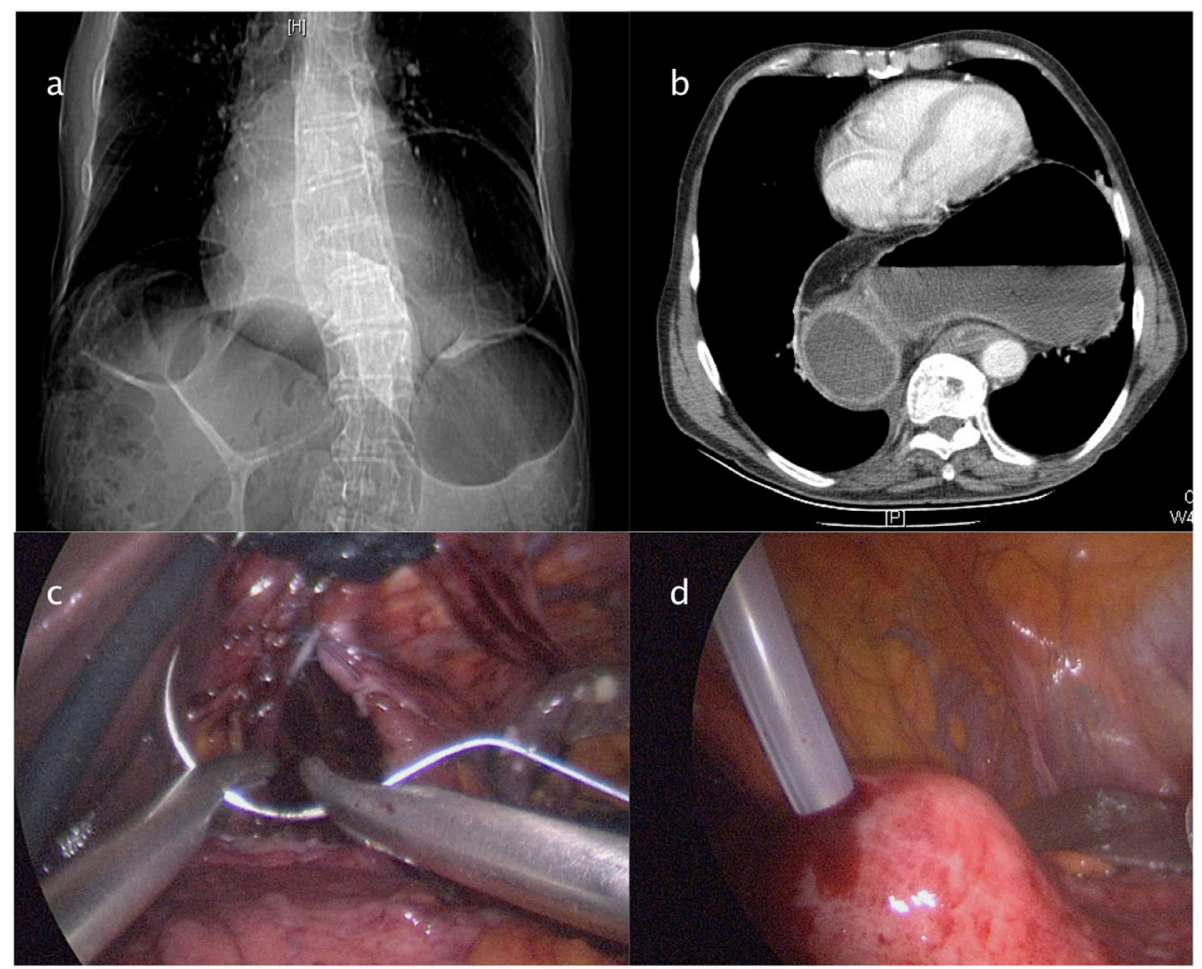

Fig. 6 Case 3: Preoperative radiologic exams and endoscopic treatment. a Chest radiography showing migration of the stomach in the chest. $\mathbf{b}$ CT scan showing the stomach volvulus. c Crura closure by intracorporeal stitches. d Percutaneous endoscopic gastrostomy (PEG) 


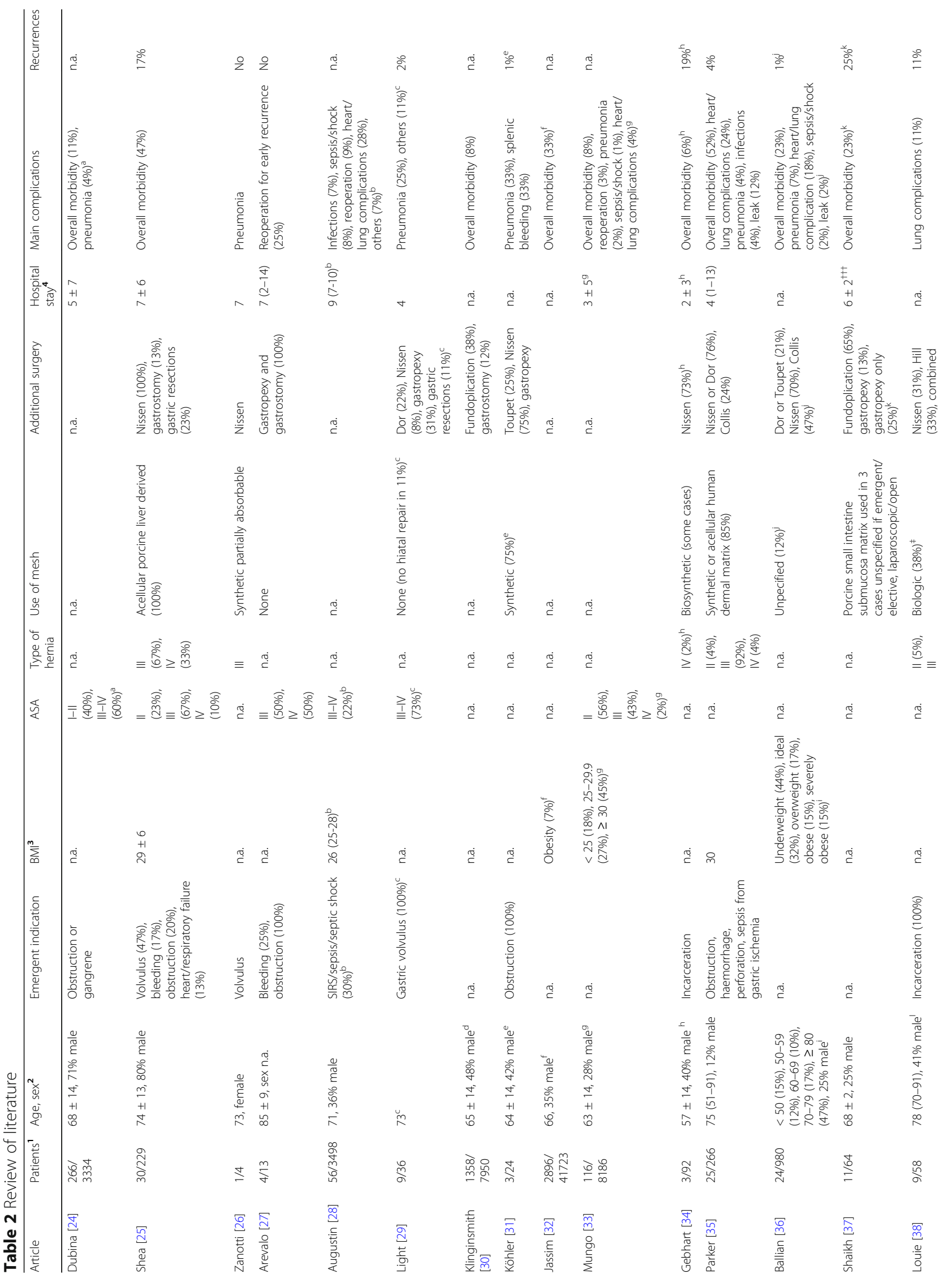




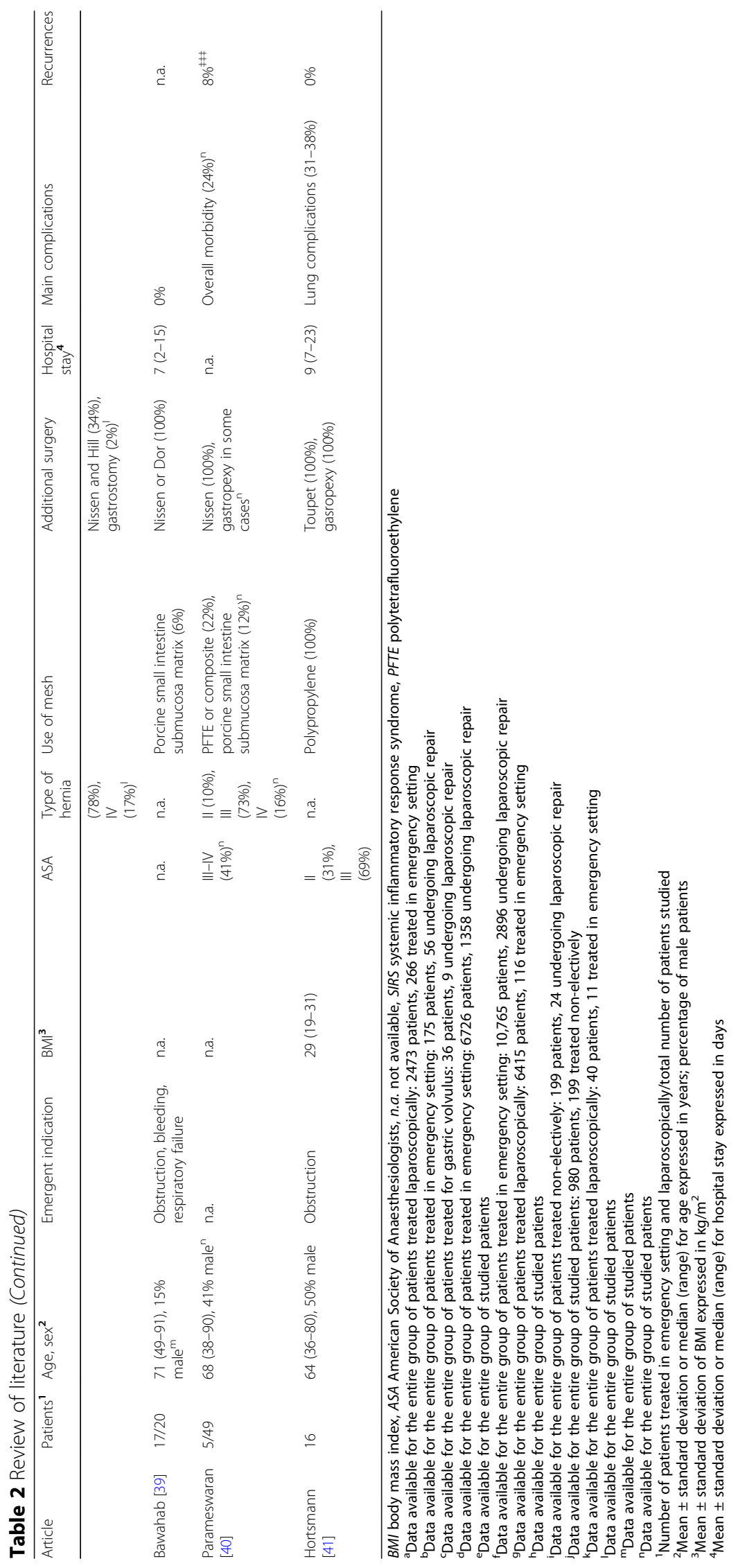


patients' characteristics were used to create a mortality and significant morbidity predictive model for GHH repair [16]. The 2013 Society of American Gastrointestinal and Endoscopic Surgeons (SAGES) guidelines recommend repair of all symptomatic paraesophageal hernias [20].

Literature suggests that patients with acute paraesophageal hernia are often overweight/obese (average body mass index from 29 to $\left.30 \mathrm{~kg} / \mathrm{m}^{2}\right)[25,35,41]$ and with an American Society of Anaesthesiologists (ASA) score of III or higher (69-100\%) [25, 27, 41].

Emergency surgery for incarcerated-strangulated GHH is mandatory especially in the presence of the classic Borchardt's triad, consisting in retching, epigastric pain and failure to place a nasogastric tube. Generally, the patients present acutely with thoracic/abdominal pain and symptoms of mechanical gastric outlet obstruction (20$100 \%)[25,27,29,31]$ or upper gastrointestinal bleeding $(17-25 \%)[25,27]$. A chest X-ray should be the first diagnostic tool to rule out other diagnoses and to detect perforating signs $[1,20]$. According to the selected articles, respiratory failure $[25,39]$ or even sepsis and shock $[28,35]$ are other possible acute presentations that appear to be the evolution of gastric ischemia. These unstable patients are often obliged to undergo immediate open surgery.

A chest-abdominal contrast-enhanced CT scan and upper endoscopy are the most important exams to be performed during the pre-operative workup. Endoscopy should be attempted with the aim of decompressing the stomach, having a direct view of mucosal condition (gastric ischemia), and trying a conservative management. Bleeding and gastric perforation, with septic sequelae, represent the clinical evolution if treatment is delayed.

There are no clear recommendations on the operative management of incarcerated hiatal hernia. Management algorithms for acutely presenting paraesophageal hernia were proposed on the results of a small series of patients [39]. The increased perioperative mortality and morbidity associated with the emergency repair for gastric volvulus and strangulation are reported in many series [22, 45]. Immediate open surgery is suggested in case of unstable patients. In other cases, an initial laparoscopic approach is advisable for trained surgical teams. Emergent laparoscopic $\mathrm{HH}$ reduction and repair may be carried out in cases without gastric perforation, with low morbidity rate and with the benefits of a minimally invasive approach [30, 35, 39]. The selected literature reported an average hospital stay of 4-9 days [25-27, 29, 35, 39, $41]$, overall morbidity rate of $0-52 \%[25,30,35]$ and a recurrence rate of $0-17 \%[25,29,35,38,41]$.

With a few exceptions [29], a hiatoplasty is always performed with different suture strategies (direct, pledgets and meshes). There is no evidence regarding the advisable use and type of mesh: both synthetic [26, 31, $35,40,41]$ and biologic mesh [25, 35, 37-39] have been adopted. About fundoplication, the main factors that influence the decision are gastric fundus tissue condition and the history of GERD. Nissen fundoplication is reported up to $75-100 \%$ of cases and is the most common technique [25, 31]. Additional techniques, such as gastrostomy, gastropexy, Collis procedure or gastric resections, are required in selected cases, and this underlines to what extent this surgery is tailored case by case.

Nevertheless, no previous article, among the selected ones, ever reported a predominant robotic approach for the emergent paraesophageal hernia repair. In our case series, age was not an exclusion criterion to minimally invasive approach. We believe that, in the acute setting, the concerns about the postoperative risk of recurrence are negligible compared to the risk of gastric perforation (after gastric vascular sufferance) and the absence of functional study (oesophageal manometry, swallow x-ray exam, etc.). The surgical goals, indeed, appear to be different case by case, and techniques should be carefully tailored.

This study has some limitations: the limited number of cases in our experience prevents from drawing any general conclusion; moreover, no open procedures were accounted both in emergency and in elective setting, so any comparison was not possible. Still, the selected literature shows the absence of comprehensive data about the outcome after emergent robotic-assisted repair of GHH.

\section{Conclusions}

The robotic-assisted approach in acute paraesophageal hernia repair may give advantages compared to conventional laparoscopy, for what concerns the surgeon's comfort and precision, and this is probably unique in emergency surgery. However, its use mainly depends on device availability and the surgical team's experience.

We can conclude, on the basis of current literature, that it is challenging to stigmatise recommendations for the management of GHH in an emergency setting. In many cases, a minimally invasive approach is possible and safe, with good peri- and postoperative outcomes. Robotic surgery may represent an appealing option to ease some surgical steps as dissection, abdominal reduction and suturing.

\section{Abbreviations}

GHH: Giant hiatal hernia; CT: Computed tomography; HH: Hiatal hernia; GERD: Gastroesophageal reflux disease; OAT: Oral anticoagulant therapy; SAGES: Society of American Gastrointestinal and Endoscopic Surgeons; ASA: American Society of Anaesthesiologists

Acknowledgements Not applicable. 


\section{Authors' contributions}

GCe: study design, collection of data, drafting, figures; AP: drafting, review of literature, tables; WB: drafting, review of literature; MDR: drafting, review of literature; FC: critical revision; FR: literature search; GCo: literature search; AR: literature search; ML: drafting; MT: critical revision. All authors read and approved the final manuscript.

\section{Funding}

The authors declare that they received no funding

\section{Availability of data and materials}

All data generated or analysed during this study are included in this published article.

\section{Ethics approval and consent to participate}

All patients gave consent for participating in the study. The need for ethics approval was waived because of the case series design

\section{Consent for publication}

All patients gave consent for publication.

\section{Competing interests}

The authors declare that they have no competing interests.

\section{Author details}

'General Surgery, "San Giovanni Battista" Hospital, USL Umbria 2, Via Massimo Arcamone 1, 06034 Foligno, Italy. ${ }^{2}$ Unit of General Surgery "V. Bonomo", Department of Biomedical Sciences and Human Oncology, University of Bari "A. Moro", Polyclinic of Bari, Piazza Giulio Cesare 11, 70124 Bari, Italy. ${ }^{3}$ Department of Emergency and Trauma Surgery, Parma University Hospital, Viale Antonio Gramsci 11, 43126 Parma, Italy. ${ }^{4}$ Department of Medicine and Health Sciences "V. Tiberio", University of Molise, Via Francesco de Sanctis 1, 86100 Campobasso, Italy.

\section{Received: 15 March 2020 Accepted: 14 May 2020} Published online: 01 June 2020

\section{References}

1. Kahrilas PJ, Kim HC, Pandolfino JE. Approaches to the diagnosis and grading of hiatal hernia. Best Pract Res Clin Gastroenterol. 2008;22:601-16.

2. Mitiek MO, Andrade RS. Giant hiatal hernia. Ann Thorac Surg. 2010;89: S2168-73.

3. Luketich JD, Nason KS, Christie NA, Pennathur A, Jobe BA, Landreneau RJ, et al. Outcomes after a decade of laparoscopic giant paraesophageal hernia repair. J Thorac Cardiovasc Surg. 2010;139:395-404.

4. Larusson HJ, Zingg U, Hahnloser D, Delport K, Seifert B, Oertli D. Predictive factors for morbidity and mortality in patients undergoing laparoscopic paraesophageal hernia repair: age, ASA score and operation type influence morbidity. World J Surg. 2009:33:980-5.

5. Shafii AE, Agle SC, Zervos EE. Perforated gastric corpus in a strangulated paraesophageal hernia: a case report. J Med Case Rep. 2009;3:6507.

6. Díez Ares JÁ, Peris Tomás N, Estellés Vidagany N, Periáñez GD. Gastric necrosis secondary to strangulated giant paraesophic hiatal hernia. Rev Esp Enferm Dig. 2016;108:498-500.

7. Sheff SR, Kothari SN. Repair of the giant hiatal hernia. J Long-term Effects Med Implants. 2010;20:139-48.

8. Mori T, Nagao G, Sugiyama M. Paraesophageal hernia repair. Ann Thorac Cardiovasc Surg. 2012:18:297-305.

9. Cuschieri A, Shimi S, Nathanson LK. Laparoscopic reduction, crural repair and fundoplication of large hiatal hernia. Am J Surg. 1992;163:425-30.

10. Obeidat FW, Lang RA, Knauf A, Thomas MN, Huttl TK, Zugel NP, et al. Laparoscopic anterior hemifundoplication and hiatoplasty for the treatment of upside-down stomach: mid- and long-term results after 40 patients. Surg Endosc. 2011;25:2230-5.

11. Engstrom C, Cai W, Irvine T, Devitt PG, Thompson SK, Game PA, et al. Twenty years of experience with laparoscopic antireflux surgery. $\mathrm{Br}$ J Surg. 2012;99:1415-21.

12. Dallemagne B, Quero G, Lapergola A, Guerriero L, Fiorillo C, Perretta S. Treatment of giant paraesophageal hernia: pro laparoscopic approach. Hernia. 2018;22:909-19.
13. Ceccarelli G, Patriti A, Biancafarina A, Spaziani A, Bartoli A, Bellochi R, et al. Intraoperative and postoperative outcome of robot-assisted and traditional laparoscopic Nissen fundoplication. Eur Surg Res. 2009;43:198-203.

14. Hosein S, Carlson T, Flores L, Rodrigues Armijo P, Oleynikov D. Minimally invasive approach to hiatal hernia repair is superior to open, even in the emergent setting: a large national database analysis. Surg Endosc. 2020. https://doi.org/10.1007/s00464-020-07404-y.

15. Schiergens TS, Thomas MN, Hüttl TP, Thasler WE. Management of acute upside-down stomach. BMC Surg. 2013;13:55.

16. Banki F. Giant paraesophageal hiatal hernia: a complex clinical entity. J Thorac Cardiovasc Surg. 2017;154:752-3.

17. Oelschlager BK, Pellegrini CA, Hunter J, Soper N, Brunt M, Sheppard B, et al. Biologic prosthesis reduces recurrence after laparoscopic paraesophageal hernia repair: a multicenter, prospective, randomized trial. Ann Surg. 2006; 244:481-90.

18. Dallemagne B, Kohnen L, Perretta S, Weerts J, Markiewicz S, Jehaes C. Laparoscopic repair of paraesophageal hernia. Long-term follow-up reveals good clinical outcome despite high radiological recurrence rate. Ann Surg. 2011;253:291-6.

19. Jobe BA, Horvath KD, Swanstrom LL. Postoperative function following laparoscopic Collis gastroplasty for shortened esophagus. Arch Surg. 1998; 133:867-74.

20. Kohn GP, Price RR, DeMeester SR, Zehetner J, Muensterer OJ, Awad Z, et al. SAGES guidelines committee. Guidelines for the management of hiatal hernia. Surg Endosc. 2013;27:4409-28.

21. Mattioli S, Lugaresi M, Ruffato A, Daddi N, Di Simone MP, Perrone O, et al. Collis-Nissen gastroplasty for short oesophagus. Multimed Man Cardiothorac Surg. 2015;18:2015.

22. Sihvo El, Salo JA, Rasanen JV, Rantanen TK. Fatal complications of adult paraesophageal hernia: a population-based study. J Thorac Cardiovasc Surg. 2009;137:419-24.

23. Stylopoulos N, Rattner DW. Paraesophageal hernia: when to operate? Adv Surg. 2003;37:213-29.

24. Dubina ED, Moazzez A, Park H, Shover A, Kim DY, Simms ER. Predictors of morbidity and mortality in complex paraesophageal hernia repair: a NSQIP analysis. Am Surg. 2019:85:1189-93.

25. Shea B, Boyan W, Decker J, Almagno V, Binenbaum S, Matharoo G, et al. Emergent repair of paraesophageal hernias and the argument for elective repair. JSLS. 2019;23.

26. Zanotti D, Fiorani C, Botha A. Beyond Belsey: complex laparoscopic hiatus and diaphragmatic hernia repair. Ann R Coll Surg Engl. 2019;101:162-7.

27. Arevalo G, Wilkerson J, Saxe J. Acute paraesophageal hernia: laparoscopic repair with adjunct T-fastener gastropexy for the high operative risk patient. Surg Laparosc Endosc Percutan Tech. 2018;28:123-7.

28. Augustin T, Schneider E, Alaedeen D, Kroh M, Aminian A, Reznick D. Emergent surgery does not independently predict 30-day mortality after paraesophageal hernia repair: results from the ACS NSQIP database. J Gastrointest Surg. 2015;19:2097-104.

29. Light D, Links D, Griffin M. The threatened stomach: management of the acute gastric volvulus. Surg Endosc. 2016;30:1847-52.

30. Klinginsmith $\mathrm{M}$, Jolley J, Lomelin D, Krause C, Heiden J, Oleynikov D. Paraesophageal hernia repair in the emergency setting: is laparoscopy with the addition of a fundoplication the new gold standard? Surg Endosc. 2016; 30:1790-5.

31. Köhler G, Koch OO, Antoniou SA, Emmanuel K, Pointner R. "Acute intrathoracic stomach!" how should we deal with complicated type IV paraesophageal hernias? Hernia. 2015;19:627-33.

32. Jassim H, Seligman JT, Frelich M, Goldblatt M, Kastenmeier A, Wallace J, et al. A population-based analysis of emergent versus elective paraesophageal hernia repair using the Nationwide inpatient sample. Surg Endosc. 2014;28:3473-8.

33. Mungo B, Molena D, Stem M, Feinberg RL, Lidor AO. Thirty-day outcomes of paraesophageal hernia repair using the NSQIP database: should laparoscopy be the standard of care? J Am Coll Surg. 2014;219:229-36.

34. Gebhart A, Vu S, Armstrong C, Smith BR, Nguyen NT. Initial outcomes of laparoscopic paraesophageal hiatal hernia repair with mesh. Am Surg. 2013; 79:1017-21.

35. Parker DM, Rambhajan A, Johanson K, Ibele A, Gabrielsen JD, Petrick AT. Urgent laparoscopic repair of acutely symptomatic PEH is safe and effective. Surg Endosc. 2013;27:4081-6. 
36. Ballian N, Luketich JD, Levy RM, Awais O, Winger D, Weksler B. A clinical prediction rule for perioperative mortality and major morbidity after laparoscopic giant paraesophageal hernia repair. J Thorac Cardiovasc Surg. 2013:145:721-9.

37. Shaikh I, Macklin P, Driscoll P, de Beaux A, Couper G, Paterson-Brown S. Surgical management of emergency and elective giant paraesophageal hiatus hernias. J Laparoendosc Adv Surg Tech A. 2013;23:100-5.

38. Louie BE, Blitz M, Farivar AS, Orlina J, Aye RW. Repair of symptomatic giant paraesophageal hernias in elderly (>70 years) patients results in improved quality of life. J Gastrointest Surg. 2011;15:389-96.

39. Bawahab M, Mitchell P, Church N, Debru E. Management of acute paraesophageal hernia. Surg Endosc. 2009;23:255-9.

40. Parameswaran R, Ali A, Velmurugan S, Adjepong SE, Sigurdsson A. Laparoscopic repair of large paraesophageal hiatus hernia: quality of life and durability. Surg Endosc. 2006;20:1221-4.

41. Horstmann R, Klotz A, Classen C, Palmes D. Feasibility of surgical technique and evaluation of postoperative quality of life after laparoscopic treatment of intrathoracic stomach. Langenbeck's Arch Surg. 2004;389:23-31.

42. Weber C, Davis CS, Shankaran V, Fisichella PM. Hiatal hernias: a review of the pathophysiologic theories and implication for research. Surg Endosc. 2011;25:3149-53.

43. Curci JA, Melman LM, Thompson RW, Soper NJ, Matthews BD. Elastic fiber depletion in the supporting ligaments of the gastroesophageal junction: a structural basis for the development of hiatal hernia. J Am Coll Surg. 2008; 207:191-6.

44. Asling B, Jirholt J, Hammond P, Knutsson M, Walentinsson A, Davidson G, et al. Collagen type III alpha I is a gastro-oesophageal reflux disease susceptibility gene and a male risk factor for hiatus hernia. Gut. 2009;58: 1063-9.

45. Poulose BK, Gosen C, Marks JM, Khaitan L, Rosen MJ, Onders RP, et al. Inpatient mortality analysis of paraesophageal hernia repair in octogenarians. J Gastrointest Surg. 2008;12:1888-92.

\section{Publisher's Note}

Springer Nature remains neutral with regard to jurisdictional claims in published maps and institutional affiliations.

Ready to submit your research? Choose BMC and benefit from:

- fast, convenient online submission

- thorough peer review by experienced researchers in your field

- rapid publication on acceptance

- support for research data, including large and complex data types

- gold Open Access which fosters wider collaboration and increased citations

- maximum visibility for your research: over $100 \mathrm{M}$ website views per year

At $\mathrm{BMC}$, research is always in progress.

Learn more biomedcentral.com/submissions 